\title{
AS AFINIDADES SELVAGENS: MAIO DE 68, JUNHO DE 2013
}

\section{SAVAGE AFFINITIES: MAY 68, JUNE 2013}

\author{
Murilo Duarte Costa Corrêa*
}

Resumo: As afinidades selvagens ensaia traçar linhas de aproximação entre o maio de 68 francês e o junho de 2013 brasileiro, e foi apresentado oralmente durante o ciclo comemorativo do Maio de 68 - 50 anos em movimento, em Ponta Grossa - Paraná, no primeiro semestre de 2018. A partir de um diálogo metalinguístico e político entre os signos que o Maio de 68 produziu e a emergência de uma nova cena intelectual que ficou conhecida como pós-estruturalismo francês, o ensaio percorre uma série de afinidades eletivas entre o Maio francês e o Junho brasileiro, discutindo como essas lutas transformaram o papel dos intelectuais, sua relação com o campo social e político, o caráter jovem das rebeliões e sua abertura para o comum das lutas, sua relação com a democracia, com o cotidiano vivido e com um horizonte de futurição política.

Palavras-chave: Maio de 68; Junho de 2013; Pós-estruturalismo francês.

ABSTRACT: Savage affinities is an essay which draws proximity lines concerning the protests of May 68 in France and of June 2013 in Brazil. A first draft of this essay was orally presented at the "Commemorative Cicle of May 68 - 50 years of uprisings", in Ponta Grossa, Paraná, Brazil, in 2018's first semester. We propose a metalinguistic and political dialogue which arises from an ensemble of May 68 signs and the emergence of an unprecedented intellectual scenario that is currently acknowledged as French Theory. The key argument travels through a series of elective affinities among the French May and the Brazilian June, and discusses the various ways in which those uprisings transformed the role of intellectuals, their connection to the social and the political fields, the young characteristic of rebellions and its openness to the common ground of political struggles, reconfiguring notions as democracy, everyday life and the horizons of a collective future.

KeY-words: May 68; June 2013; French Theory.

\footnotetext{
"Professor Adjunto de Teoria Política da Faculdade de Direito e do Programa de Pós-Graduação em Ciências Sociais Aplicadas da UEPG, Mestrado e Doutorado. Affiliated researcher da Faculty of Law and Criminology da Vrije Universiteit Brussel, Bélgica, onde realizou estágio de pós-doutorado sobre a filosofia do campo social em Gilles Deleuze. Doutor (USP) e Mestre (UFSC) em Filosofia e Teoria Geral do Direito. Coordena o Laboratório de Pesquisa Interdisciplinar em Teoria Social/ Teoria Política e Pós-Estruturalismo (LABTESP, PPGCSA/UEPG). Co-organizou $O$ estado de exceção e as formas jurídicas (Editora UEPG, 2017) e Pensar a Netflix: séries de pop filosofia e política (D'Plácido, 2018). Traduziu Deleuze, a prática do direito, de Laurent de Sutter (Editora UEPG, 2019). Escreveu, entre outros livros, Direito e Ruptura: ensaios para uma filosofia do direito na imanência (Juruá, 2013) e Filosofia Black Bloc (Circuito, 2020 [no prelo]). Email: mdc.correa@gmail.com
} 


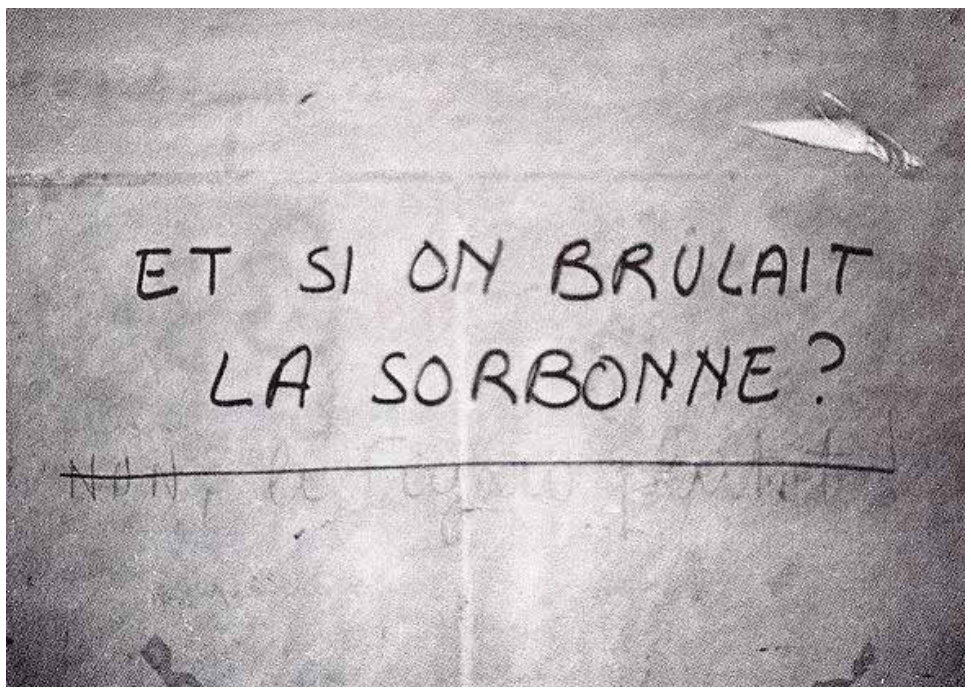

Fonte: vide nota de rodapé

\section{Para dar UM Fim aos INTElectuais}

“E se nós queimássemos a Sorbonne?”, perguntava uma parede. Entre paralelepípedos e barricadas, na umidade das ruas e da quente promessa dos corpos incendiários, maio de 68 remete a uma teia de filósofos e conceitos mais ou menos estelares. Sartre e o engajamento; Foucault e a crítica da atualidade; Deleuze e o acontecimento. No entanto, ao sermos capturados pelos conceitos e pelos nomes próprios que os enunciavam, perdemos contato com uma sensibilidade mais fina e nervosa para tatear o solo do maio de 68; para fazer corpo com a matéria social e política em movimento que pôde produzir esses conceitos e nomes próprios; isto é, um pensamento potente porque à altura do acontecimento.

É impossível compreender maio de 68, ou junho de 2013, se continuarmos a pensá-los em função dos intelectuais. Muito aquém disso, conviria pensar os intelectuais a partir dos acontecimentos, segundo um regime de dupla captura, de devir assimétrico. Seria preciso reposicionar os problemas, inverter o ângulo de visão. A pergunta a ser feita não é "com que categorias se pode pensar maio de 68, ou junho de 2013?”, mas, principalmente, como esses acontecimentos contribuem para tornar pensável o ato mesmo de pensá-los? Isto é, como um acontecimento engendra o pensar no pensamento? Que possibilidades de pensar um evento instaura por invenção? Que abalos nas certezas e nas formas de sensibilidade socialmente compartilhadas são gerados pelo acontecimento; e como o acontecimento mesmo, em seus próprios termos, torna essas rupturas instauradoras - com as quais não se confunde - sensíveis e pensáveis?

\footnotetext{
${ }^{1}$ Todas as imagens reproduzidas neste ensaio têm por fonte o site $<$ https://inventin.lautre.net/graffiti.html $>$, que possui um catálogo ainda mais vasto de graffitis de maio de 68 ".
} 
Ou o intelectual é um paralelepípedo de uma rua úmida de Paris, uma pedra portuguesa do centro bafejante do Rio de Janeiro, um bloco de concreto armado arrancado a um muro poluído da Avenida Paulista, ou não será nada. O que acontecimentos como maio de 68 ou junho de 2013 deixam como lição é que os intelectuais profissionais entendem muito pouco dos movimentos reais; e ou os seus conceitos são armas que desenvolvem o social em movimento - e, principalmente, fazem avançar o caráter movente do social -, ou seus conceitos serão impotentes para o pensamento. Pensar é sempre uma questão de ser afetado por uma dinâmica que habita o Fora do pensamento e, todavia, o instaura.

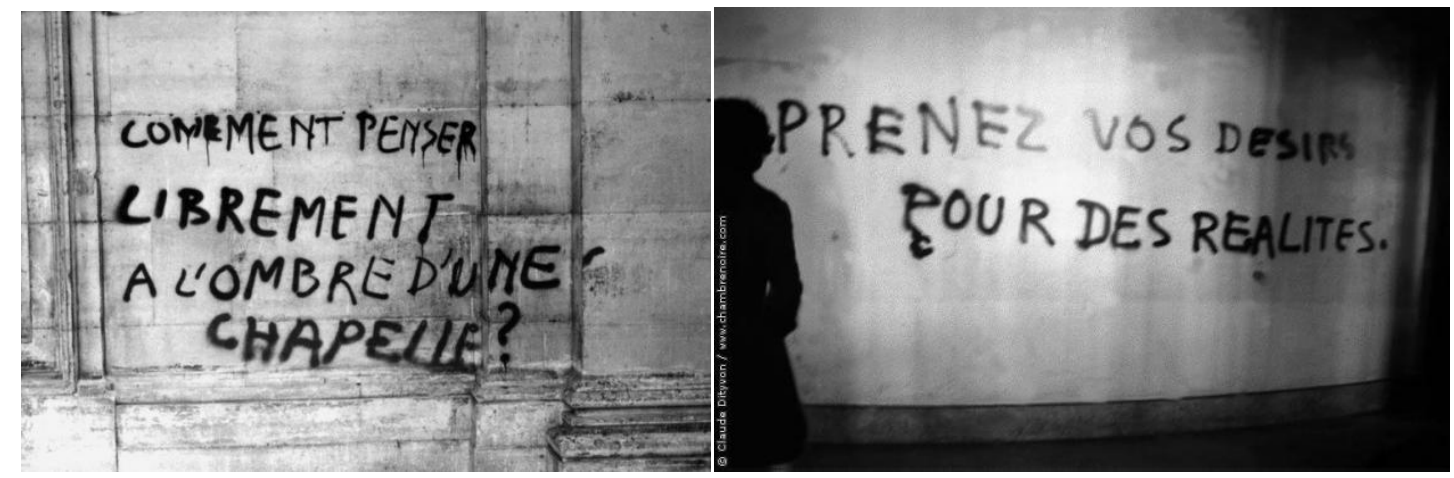

\section{Pensar o social}

Como pensar à sombra de uma capela? Ao contrário dos intelectuais, e da triste liturgia de suas Igrejas, o social pensa. Os intelectuais obtêm prazer fundamentalmente ao adotar duas atitudes detestáveis: uma perversa, outra obsessiva. A atitude perversa consiste em portar-se como fiador do progresso, como vanguarda da elevação da consciência das massas - quando os movimentos reais da vida ensinam continuamente que a matéria da política não é a consciência, mas o desejo e sua multiplicidade libidinal indomável. Maio de 68 não cessou de enunciar: tomem seus desejos por realidades; junho de 2013 foi a expressão explosiva de multiplicidades de desejos sociais, de puro "tesão" político. Um momento em que as ruas quiseram tudo e o exigiram sem modos. A atitude obsessiva é a do intelectual que crê ser o decifrador de uma realidade mais ou menos oculta, mais ou menos indecifrável, e que exige uma sensibilidade especial e exclusiva - quando sabemos que o real não está "por detrás" das cortinas, e a política é menos uma questão de decifração iluminista que de fabulação coletiva.

Essas duas posturas intelectuais - mais comuns do que imaginamos - apreendem os movimentos sociais por aquilo que eles não são: antimovimentos narcísicos ou estases antissociais. E ao invés de proporcionar o pensamento, portar-se como o líder intelectual perverso ou como o decodificador maçônico obcecado é transformar a política ora em um negócio 
privado e autoritário - rua de mão única que todos deveriam seguir -, ora em prática paranoica e estanque, que subtrai do social o seu elemento movente e plural, múltiplo e incoerente.

Há décadas, temos chamado essas posturas estáticas e narcisistas de "pensar os movimentos sociais", no Brasil: o ato de ignorar catedraticamente tanto o social e seu caráter múltiplo, quanto o movimento e seu caráter dinâmico. Insistimos em rasurar com as pretensões interessadas do "Pensamento" o fundo radicalmente anárquico sobre o qual o desejo costura o social em movimento (e tomo a liberdade de utilizar essa expressão em sentido etimológico, como junção do prefixo "an"e do radical "arkhé", do grego antigo, querendo significar a negação da possibilidade de ser comandado, governado por outrem). Só se pode repôr o social em movimento, rechaçar as estratégias de poder que o conformam, instaurando nele um princípio que o torna ingovernável, isto é, "anárquico" em sentido etimológico.

Para pensar o social é preciso dar um fim aos intelectuais e reconhecer que o social pensa, e pensa de acordo com uma lógica das multiplicidades, impassível de homogenização, unificação, condução, governo. Sua lógica é a da invenção e a do contágio; do agenciamento selvagem, da afinidade eletiva e da contaminação híbrida, sem espaço para a paranoia da pureza. Não há aqui nada do velho materialismo histórico-dialético - que, reconheçamos, tem sido brandido entre nós muito mais como um wishful thinking historicista e abstrato do que como pulsão movente ou materialista; o que há, sim, é a lógica aberrante da multiplicação das diferenças antagonistas, contra uma dada formação social, que é também uma forma de viver, uma micropolítica do cotidiano, um tecido fino de obrigações infinitas e poderes infinitesimais a esmagar a vida.

Reconhecer isso deveria converter o intelectual à bem-vinda e humilde condição de ser uma singularidade sensível e pensante entre outras, em meio à multiplicidade movente de um campo social; obrigaria a reconhecer o fato de que em eventos como maio de 68 ou junho de 2013, tanto a condição de sujeito político ativo quanto de intelectual se generaliza. Pensar, sentir e agir tornam-se condições comuns. Condições para a constituição do comum das lutas. Condições transcendentais (que não são nem espontâneas, nem estão dadas a priori) para a instauração de uma abertura ou brecha política em que estão em jogo nossos territórios existenciais e a ecologia política de nossas relações.

Se esses eventos podem ser descritos como a violenta irrupção do reprimido ou do forcluído político na superfície luminosa do corpo social, sua inteligência própria - a potência para inventar as condições coletivas que repõem o social em movimento - nada tem a ver com uma intelectualidade profissional e acadêmica em que as ideias domesticadas se repetem e circulam. Esses eventos são um movimento e uma expressão da vida, não da cultura e, "A cultura", diziam os muros de Paris naqueles dias de Maio, "é a inversão da vida". 


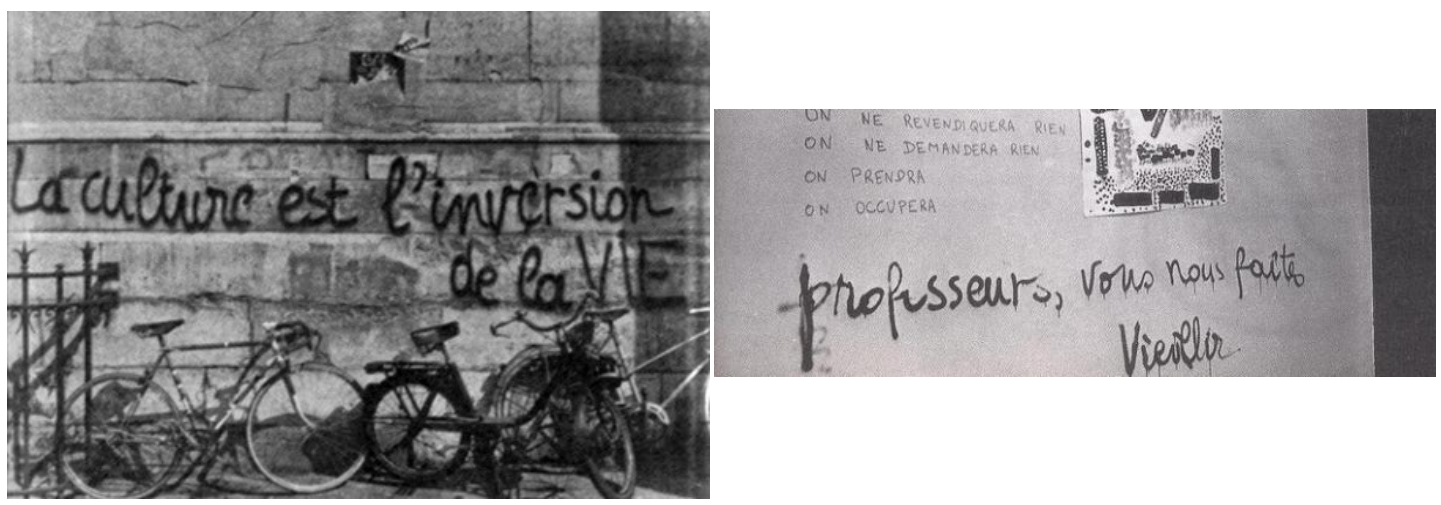

\section{O social E O POLÍtico}

Um movimento social é o útero de um mundo por vir, em que se inventam novas condições coletivas para sentir e pensar. Dele podem decorrer eventos na medida em que estes instauram rupturas; acontecimentos depois dos quais nem o mundo que nos cerca permanece pensável por nossas velhas categorias, nem a vida pode ser experimentada segundo os modos da nossa ultrapassada sensibilidade. Cortando na própria carne e a quente, seria preciso reconhecer que os professores nos fazem envelhecer.

Algo se passou, de modo que a intelectualidade deixou de ser a condição profissional atrelada a um título ou a uma posição institucional, geralmente universitária, para se tornar o elemento de um Intelecto Geral no qual os intelectuais poderão, no máximo, banhar-se, pegar carona, mapear devires, seguir de perto suas linhas de fuga, desenvolver uns petit trucs théoriques. Já não lhes cumpre elaborar direções para roteiros conceituais porque, no calor do acontecimento, são os roteiros que não cessam de elaborar e reelaborar direções impensadas, exigir os conceitos e desgastar as fixações identitárias.

A condição de uma intelectualidade geral, horizontal, radicalmente igualitária, constitui-se a partir do momento em que se generaliza no comum das lutas a dissolução de uma distinção que muitos ainda creem ser estruturante de nossas sociedades de capitalismo avançado; a divisão entre o pensamento e o labor, entre as formas intelectuais e materiais do trabalho, entre os que se ocupam do fato bruto da dominação e os que se ocupam de fabricar idealmente suas infinitas sutilezas espirituais. Que essa intelectualidade geral se processe no campo social, como condição e como efeito de um conjunto de práticas políticas, é uma circunstância prenhe de consequências significativas.

Maio de 68 e junho de 2013 são alguns dos momentos clarividentes dos últimos 50 anos em que a separação artificial entre o social e o político foi temporariamente suspensa. Eventos como esses produzem campos de subjetivação coletiva; colocam em jogo toda uma ecologia política de novas relações e de novos possíveis; produzem constelações mais vastas de possibilidades de sentir e pensar que ainda há pouco não estavam dadas, e que não podem 
ser propriedade de ninguém. Pelo contrário, os nomes próprios e os conceitos que estes enunciam só adquirem completo sentido quando remetidos à singularidade do campo social em que estão agenciados. Sob os fluxos de um Acontecimento, na trama tesa da sua absoluta singularidade, ou os conceitos são máquinas sociais, utilizáveis por todos, ou (assim como os intelectuais) não serão nada.

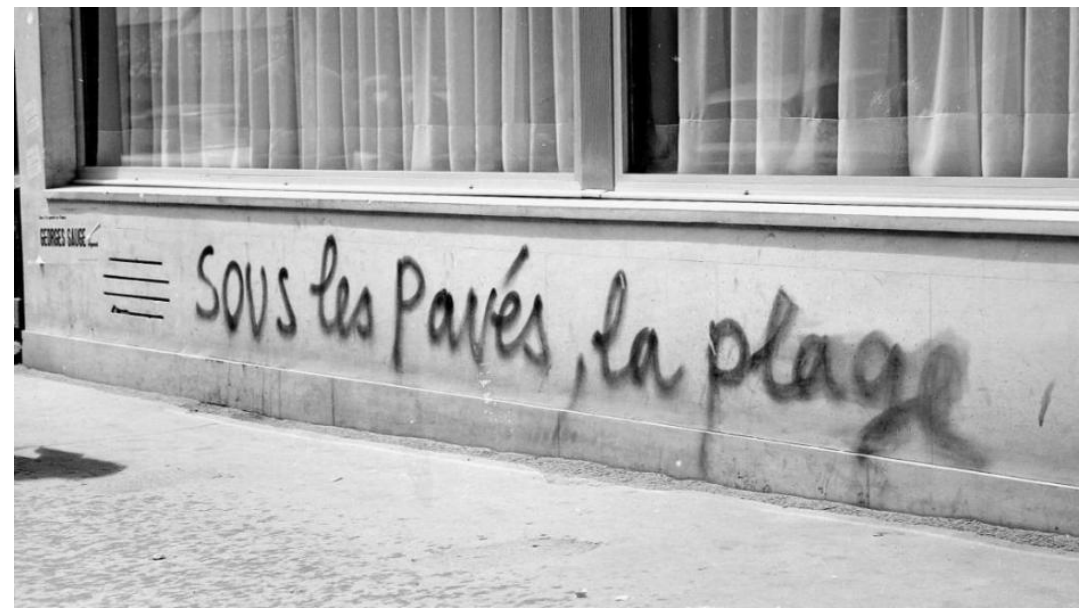

\section{As AFINIDADES SELVAGENS}

Cinquenta anos depois, ainda insiste nos muros de muitas cidades europeias este eco de maio: "Sob as calçadas, a praia". Isto é, sob a cultura, a vida. As calçadas nos separam da praia que, todavia, insiste sob nossos pés, sob uma condição espectral que conserva, subterrânea, a matéria movente. Coberta pelas calçadas, a praia é o espectro movente do real que não cessa de fluir e de ameaçar derruir, subterrâneo, a cidade imaginária que tomamos por real.

Da mesma maneira que a calçada nos separa da praia que, no entanto, permanece sob nossos pés, uma dada formação social e suas estruturas de servidão têm por função separar uma sociedade daquilo que ela pode. Assim, instauram o político como esfera separada, consagrada, intocável pelo social.

Para usar uma expressão de um etnólogo que construiu barricadas, nossas sociedades são "policiadas". Isto é, sociedades que se caracterizam pela alienação do poder em uma esfera especial, separada do corpo social. A esta alienação, nossa civilização deu o nome de Estado. No entanto, ele não se confunde com um aparato complexo, burocrático ou institucionalizado. Estado é a palavra que nomeia a operação consolidada em condição histórica, social e política que, distinguindo os governantes e governados, dividindo os que mandam e os que obedecem, procura sequestrar permanentemente o político da esfera do social. Sociedades com Estado são, portanto, aquelas em que o exercício do poder se encontra regularmente alienado, separado da totalidade do corpo social, embora a sociedade continue a ser a sua fonte e o seu objeto. 
Como a praia sob a calçada, uma sociedade se define pela variação da potência subterrânea de derruir a esfera que a separa do político.

Entre o maio de 1968 francês e o junho de 2013 brasileiro há uma série de pontos de contato. No entanto, gostaria de propor a noção de afinidades selvagens como mais do que um conjunto numeroso de coincidências significativas - como um analisador capaz de tornar visível o tipo de ação política que esses dois eventos tornaram pensável e sensível. Segundo os seus termos, creio poder definir a política não como uma ação interna aos aparelhos de Estado, mas como o movimento pelo qual um corpo social retoma o poder que dele foi separado, isto é, que o Estado alienou da sociedade na esfera do político.

Essa é a razão pela qual em maio de 68 e junho de 2013, revolta e ação política designam uma mesma prática. A política passa a ser o movimento de criação de diferenças pelo qual uma sociedade confronta o Estado e o poder separado, isto é, um movimento da sociedade contra o Estado. Nesse sentido, toda política é um movimento da sociedade que tende a conjurar a forma-Estado, isto é, o poder separado e os binarismos que estruturam nossas sociedades divididas e policiadas.

Essa é a afinidade selvagem, o eixo comum de sentido, que permite reunir maio de 68 e junho de 2013 (e praticamente qualquer revolta ocorrida no Ocidente nos últimos 50 anos) sob o mesmo signo: agir politicamente é restituir ao social a esfera de poder sequestrada no Estado. Era precisamente isso o que queriam dizer os franceses quando pichavam "O poder está nas ruas, não nas urnas" ou "Os anarquistas estão sempre aí". Os corpos passam a fluir pelas ruas e o poder, pelos corpos. Todos os corpos são anárquicos em profundidade, porque nenhum corpo pode ser furtar de participar da física do poder que os envolve e sujeita. Logo, fazer política é exercer a arte da revolta, a liberdade como coragem física; é, finalmente, restituir a política sequestrada na estrutura do Estado ao campo social. Fazer movimento, abrir uma brecha para reconfigurar o social.

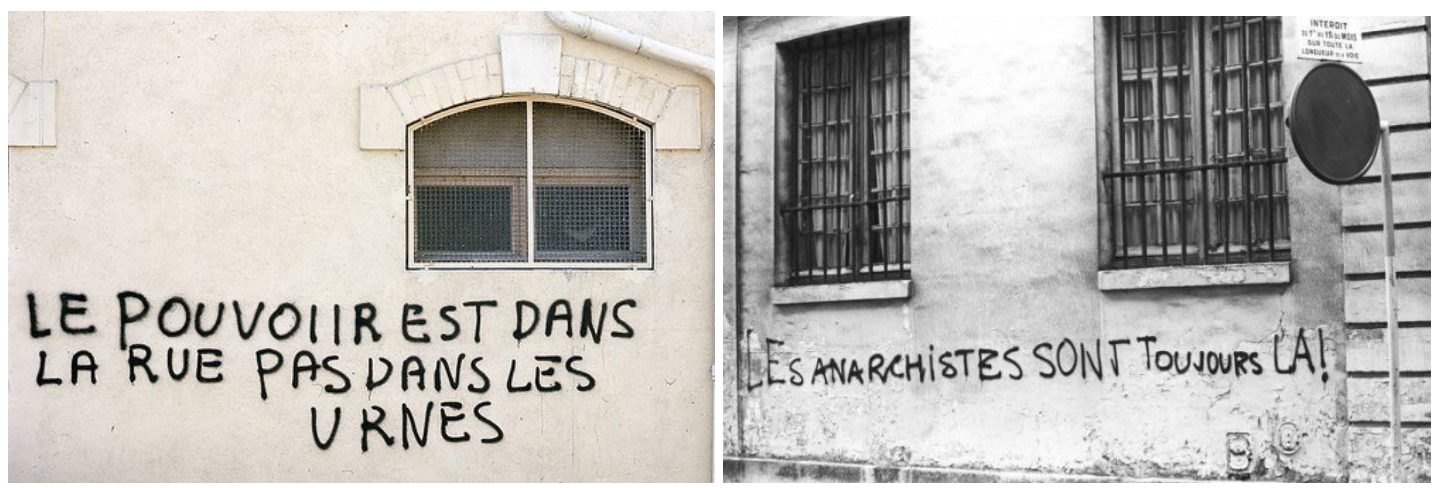




\section{REBELIÕES JOVENS, REVOLTAS MÚlTIPLAS}

Sob essa afinidade selvagem e eletiva, encontramos uma série de linhas de ataque em comum. Aqui, vou me ater a descrever rapidamente três das mais aparentes. Em primeiro lugar, tanto maio de 68 quanto junho de 2013 foram rebeliões jovens que, progressivamente, incluíram em seu âmbito um círculo social mais vasto, tornando-se rapidamente revoltas múltiplas. Eis o que designa um movimento de heterogênese: ele começa em uma ponta de subjetivação social (estudantes ou integrantes de um movimento autonomista, jovem e urbano) e, repentinamente, revolta e desejo celebram núpcias em campos de subjetivação muito mais vastos, como a fagulha em mil rastros de pólvora. Mas o fato de essas rebelióes terem por porta-vozes iniciais grupos de jovens deveria nos fazer pensar.

É razoavelmente comum na literatura sobre o maio francês ou o junho brasileiro que o protagonismo dos jovens seja rapidamente explicado em função de um recorte etário e de classe; em função de razões econômicas ou políticas que apresentam a juventude a partir de traços de incapacidade ou de impotência para o mundo que suas rebeliões confrontam. As revoltas estourariam entre os jovens, por exemplo, em razão da ausência de perspectivas de colocação no mercado de trabalho futuro, em função da precarização das condições de trabalho e de vida na metrópole, ou por conta da crise geracional ou cultural lastreada na obsolescência dos valores e costumes, ou porque suas vozes (em suposta condição de menoridade perante o real) não seriam ouvidas.

Nossos intelectuais de cercadinho não cessam de apresentar os jovens, protagonistas e catalisadores sociais das maiores revoltas dos últimos cinquenta anos, a partir dos traços negativos que os afastam do mundo bem ordenado e excludente dos adultos. Ao fazê-lo, perdem de vista aquilo que constitui a potência política específica dos jovens. Suas razões, antes de serem econômicas ou culturais, são vitalistas e políticas. Deixemos de pensar que a juventude está sempre lutando para ser inserida em um mundo cujo desaparecimento ela deseja. São os adultos que costumam lutar por sua sujeição como se se tratasse de sua salvação. Os jovens tendem a ser revolucionários porque desejam inventar o mundo que querem habitar com seus corpos e cérebros expandidos pela técnica e pelas redes, fugindo, se possível, ao controle sutil e infinitesimal que elas implicam.

Sua potência política está precisamente no fato de que os jovens são, ainda, uma classe ou ociosa ou de recente entronização nas disciplinas e controles do trabalho. E essa condição social única, geracional e temporária, que se opera no intervalo entre o fim da infância e o início da vida adulta, é um tempo de oportunidade relativamente vazio e politicamente perigoso para os poderes constituídos. Aqueles que ainda não foram suficientemente dobrados pelas disciplinas do trabalho, que zoam e escapam às disciplinas da escola, que vagabundeiam com as obrigações e tarefas domésticas, que fogem por excesso de contingente da disciplina das casernas são os que reencontram a isenção de atividades servis, o ócio, o lazer, o tempo livre 
(sinônimo de "liberdade" na Grécia antiga) como condição da política. Horizontais em suas relações, anárquicos no uso de seus corpos, indisciplinados no exercício de sua inteligência, os jovens constituem a brecha geracional que prefigura o fim da sociedade dividida.

A potência dos jovens para a política não está de forma alguma no mundo que sua ação política está deixando para trás, ou no fato de este mundo não os incluir o bastante; está na recusa vital e ativa de um mundo que outra geração deixou para trás em 68 e que nós tentamos deixar para trás em 2013. Está na capacidade de afirmar os termos de um mundo novo que precisa nascer, e que não nascerá nem das bibliotecas mofadas dos intelectuais, nem dos escritórios palacianos dos burocratas de Estado.

Eis o ridículo absurdo da responsabilização dos movimentos sociais pelos efeitos deletérios da esfera dos poderes constituídos. Desde 68, ou de 2013, tais poderes não cessaram de se reconfigurar. Os governos do $\mathrm{PT} / \mathrm{MDB}$, e a farsesca narrativa do golpe que se seguiu a 2016, correspondem precisamente a essa disputa palaciana pelos marcos de sequestro da esfera política separada da esfera social - e que não cessa de tentar reconfigurar o social à sua imagem e semelhança ainda hoje. $O$ essencial ao poder, por hora, foi obtido: suturar a brecha democrática que junho fez nascer e capturar as forças de indignação por meio de estratégias reacionárias na defesa de líderes carismáticos, messiânicos e simétricos, à esquerda e à direita.
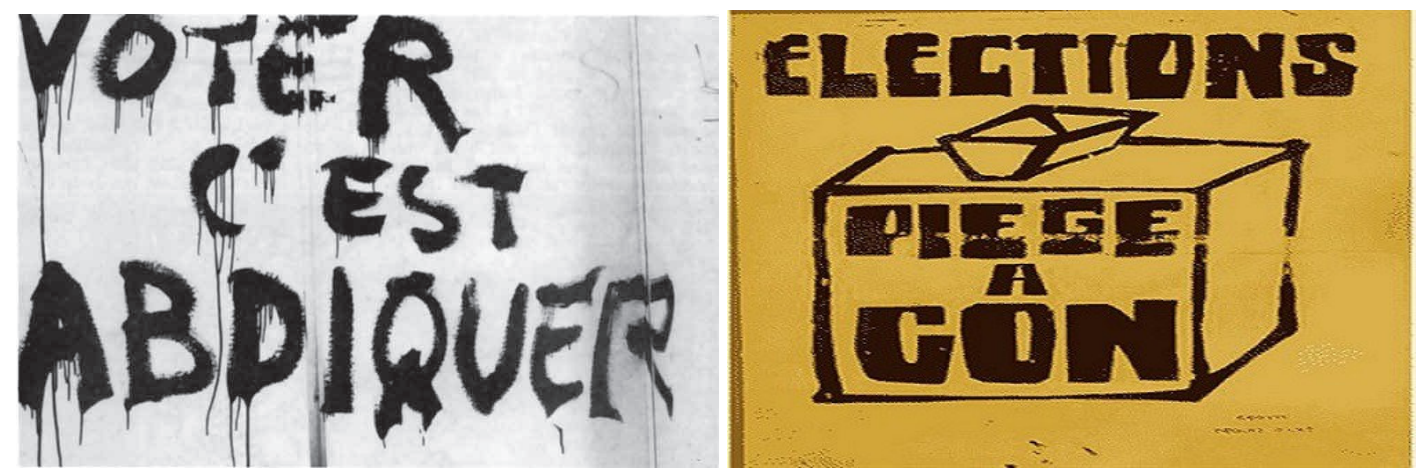

\section{VOTAR É ABDICAR}

Votar é abdicar, dizia outra parede em Paris. Eleições, armadilhas para idiotas, dizia um lambe-lambe. $\mathrm{O}$ mecanismo ficcional que esteve na mira dos estudantes e trabalhadores de 68 também foi logo reativado em 2014, no Brasil, com a farsesca reeleição da chapa DilmaTemer, com as bençãos de Lula (que hoje quer nos convencer de que o preso político é ele, e não as centenas de milhares de Rafaeis Bragas Vieiras que superlotam as masmorras desse país). Sob suas ficções, reencontramos o elemento propriamente político de maio de 68 e de junho de 2013: a retomada da esfera política pelo social. 
Eis o que chamamos de crise de representação, outro lugar comum que parece atestar a afinidade selvagem que suscitamos. Mas o que isso quer dizer? "Representação" é um termo que remete tanto à filosofia como à política. E eu arriscaria dizer que tanto lá quanto cá sua função é precisamente a mesma: separar aquele que pensa ou age do real a que seu pensamento ou sua ação se referem. A representação é como uma membrana interposta entre o ato de pensar e a coisa pensada, o ato de agir e o contexto sobre o qual se age.

Etimologicamente, representar, do latim representare, pode significar "ser a imagem ou reprodução de... [alguma coisa ou objeto real]", mas também é o que "torna presente" uma coisa ausente, "desempenha um papel", "supre a falta", "substitui", entre outros significados. Depois de junho, de uma forma ou de outra, giramos sem cessar ao redor da "democracia representativa”. Seu específico significado é algo delicado de compreender porque envolve um paradoxo. Uma democracia representativa é, ao mesmo tempo, o governo de um povo que governa, mas não governa, porque governam seus representantes; isto é, aqueles que "lhes fazem as vezes", aqueles que "tomam seu lugar", "agem como seus mandatários", "tornam presente a sua ausência".

Jacques Rancière em um livro belíssimo e poderoso afirmou que "democracia representativa" é na melhor das hipóteses um oxímoro, uma contradição em termos. Ou é "democracia" - e a plebe emite decretos (como o do fim do aumento das passagens de ônibus, ou do preço do diesel) em sua multiplicidade horizontal, rizomórfica, anárquica e indomável (uma espécie de antigoverno da multidão), ou é "representativa", e governa a casta de canalhas oligarcas. Isso talvez permita compreender as razões da revolta, ou da chamada "crise de representação".

Toda representação implica sua crise como um elemento interno ao seu funcionamento. A representação é precisamente um mecanismo que separa as singularidades plebeias da capacidade de se autodeterminar, de se autogovernar - e todos os mecanismos de participação não passam de amortecedores e instrumentos para sequestrar nosso consentimento ("você não tem poder para decidir nada, mas tem a chance de participar da escolha de quem vai decidir por você”). Conjugar a participação desigualmente democrática, ou democraticamente desigual, mal consola: "Eu participo, tu participas, ele participa, nós participamos, vós participais, ELES aproveitam", denunciava outro cartaz de maio de 68.

Levar o social a sério implica recusar até mesmo as instâncias de pressão e participação política tradicionais. Assim como junho de 2013 começou com um movimento que rechaçava bandeiras, era "apartidário" - o que jamais quis dizer anti- ou a-político, as paredes do maio de 68, entre as barricadas, também gritavam que "Os sindicatos são bordeis". Junho foi muitas coisas, e foi também uma forma de gritar: "não precisamos dos partidos para resistir". Como Maio de 68, Junho de 2013 forma uma única vaga, um movimento unívoco e antimessiânico do desejo. É a arma do desejo apontada contra a cara da política como "salvação". Prova corpórea do cruzamento entre o libidinal, o social e o político. 

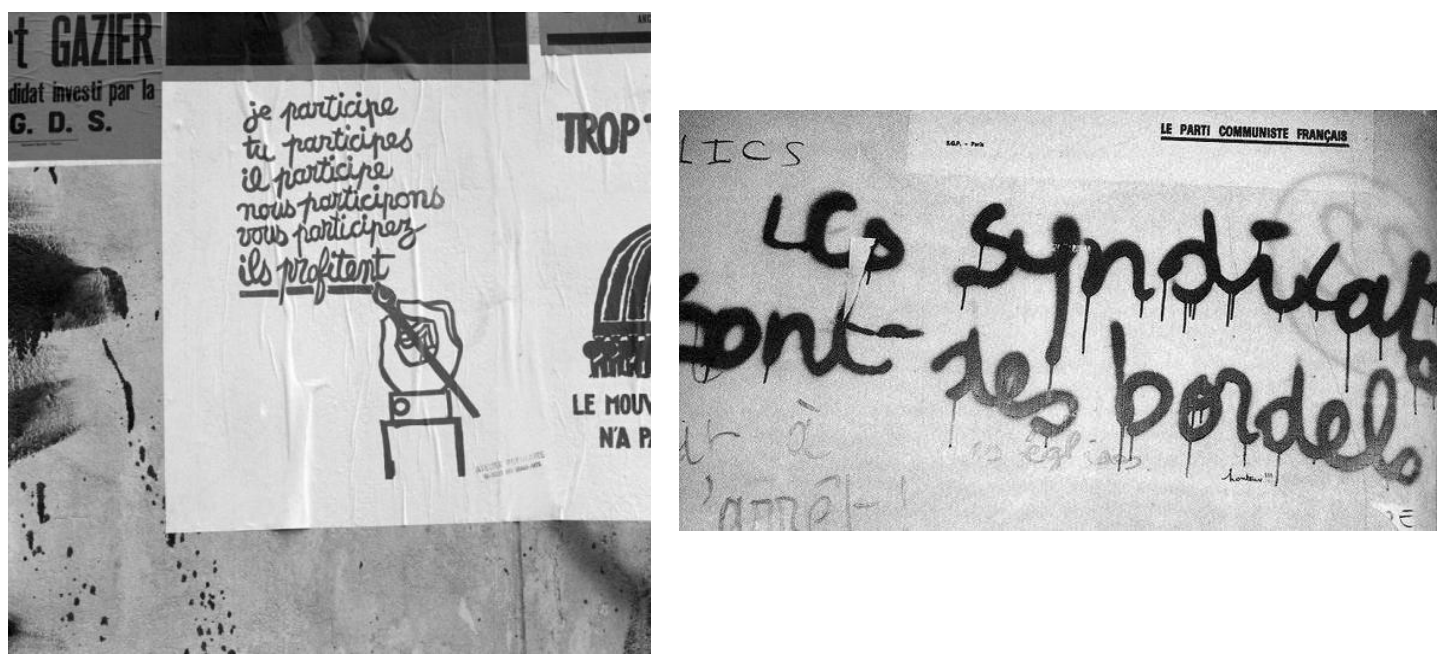

\section{Micropolítica do Cotidiano}

Em maio de 68, como em junho de 2013, estava em questão uma micropolítica do cotidiano. Aquele que fala em revolução sem mudar a vida cotidiana tem na boca um cadáver, diziam em maio. Fazer a revolução não é fazer a revolução das classes, cumprir o fim da História, realizar o Espírito do mundo, mas revolucionar o cotidiano micropoliticamente. Junho de 2013 tampouco está distante de maio de 68 sob esse aspecto, embora se diga que maio representou uma revolução na cultura e nos costumes - e talvez o junho brasileiro não tenha aparentemente significado tanto.

Seria preciso lembrar que, de um ponto de vista estratégico, junho foi uma micropolítica do cotidiano. Seu ponto de partida eram vinte centavos: o preço do transporte coletivo como condição de acesso aos bens comuns da metrópole que todos, em redes sociais de colaboração no capitalismo imaterial, auxiliamos a construir. Mas sua estratégia de luta e protesto revertia as condições precárias, lentas, caras, poluentes e irracionais dos transportes urbanos públicos e privados. Bastava impedir o acesso a algumas poucas vias dos anéis viários centrais das grandes cidades para parar completamente o trânsito e tornar visível tanto o sistema de privilégios quanto a insuportável condição comum que esmaga dia a dia o desejo de transitar nas cidades. Um nomadismo político se constituía ao parar o falso movimento metropolitano, interrompendo os fluxos da cotidianidade.

Pouco a pouco, um campo de subjetivação coletivo foi criado, tornando-se catalisador para a expressão de revoltas e demandas muito mais amplas e profundas. Logo, a multidão das ruas - acusada de "não ter pauta", ou de protestar simplesmente "contra tudo o que está aí" - queria tudo. Proliferavam demandas pela ampliação e qualificação dos serviços públicos, redução de impostos, ações diretas anticapitalistas, pedidos de renúncia de Dilma e de políticos locais, "Fora Todos", atos contra a realização dos megaeventos no Brasil (e sua política 
oligárquica, corrupta e ecocida), pautas contra a violência policial demandando informações sobre o desaparecimento do pedreiro Amarildo de Souza etc. Junho foi o empurrão para que o inconsciente desejante e político dos governados transbordasse.

A condição política comum e estratégica para esse transbordamento foi uma ativa recusa da sociedade dividida; da partilha de sujeições servis entre governantes e governados. Junho consistiu na experiência coletiva e na emergência temporária de uma democracia plebeia, horizontal e múltipla, de praças e ruas, desprovida de representantes e com capacidade para conceptualizar suas próprias lutas para muito além do que sonha a pobreza imaginativa dos nossos tristes intelectuais.

Como maio de 68, Junho de 2013 foi a sociedade contra o Estado (e o insuportável estado de coisas, hoje aprofundado). O erro é imaginar que maio de 68 , ou junho de 2013 , terminaram, quando o acontecimento permanece à nossa espera; quando o evento nunca se esgota nos fatos em que ele se atualiza. Somos sempre nós que tardamos demais. Mais do que tomar parte em um movimento social, é preciso repôr o social em movimento, fazer movimento com o social, agir para criar o povo que falta. Quando tudo parece fechado, quando nenhuma brecha ou abertura parece possível - recomendava Henri Bergson -, é preciso remexer as cinzas, soprar, fazer rescender o perfume do aberto, encontrar uma centelha, e então pôr fogo na Sorbonne, ou na cidade.

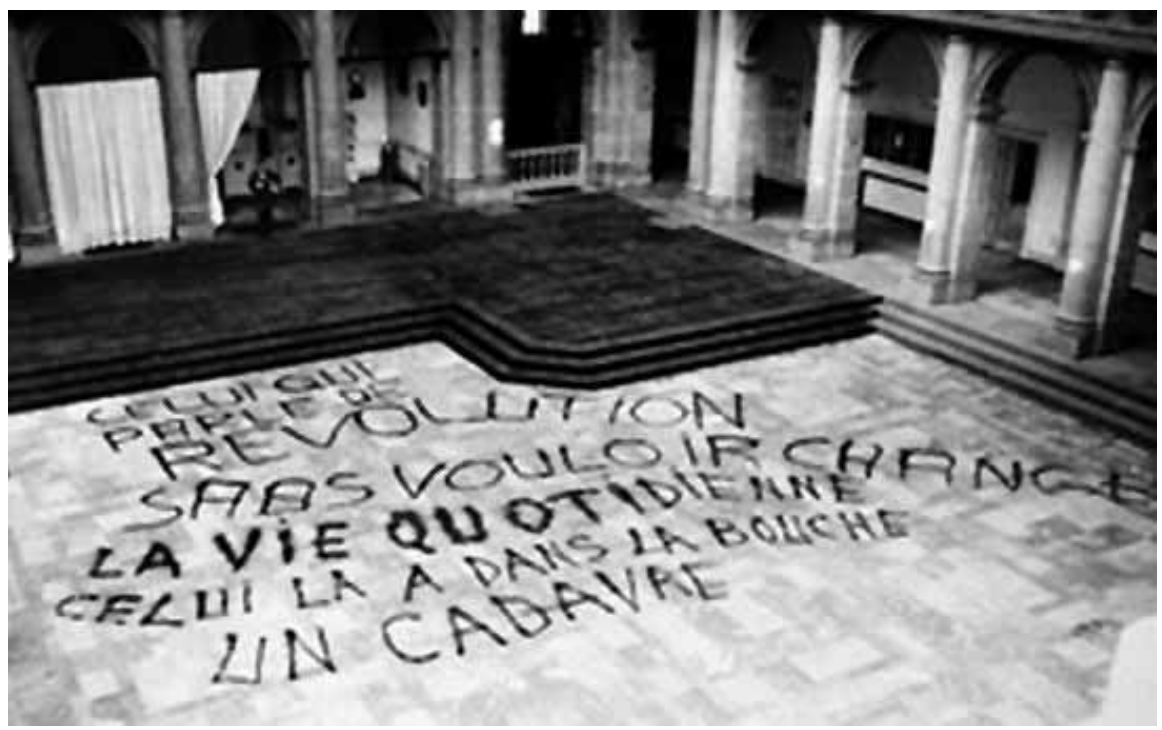

Recebido para publicação em 18 de nov. 2018 Aceito para publicação em 10 fev. 2019 